\section{The role of anxiety in binge eating behavior: a critical examination of theory and empirical literature}

\author{
Diane L. Rosenbaum, Kamila S. White \\ Department of Psychology, University \\ of Missouri - Saint Louis, St. Louis, \\ MO, USA
}

\section{Abstract}

The purpose of this manuscript is to expand the understanding of binge eating by reviewing the role of aspects of negative affect. Specifically, this paper will present evidence for further investigation of the bearing that anxiety may have in binge eating development and maintenance. A comprehensive review of the literature regarding the relation of binge eating and anxiety was performed. Valuable contributions have been made to the binge eating literature regarding some aspects of negative affect (i.e., depression); however, outside of bulimia nervosa studies, much of the theoretical and empirical binge eating research to date has not directly addressed the role of anxiety. Research supports expansion of investigations of negative emotionality and binge eating to include specific study of anxiety. Greater inclusivity and specificity in the unique contributions of various negative emotions may further the development of temporal models and intervention efforts.

\section{The role of anxiety in binge eating behavior}

Binge eating is a deleterious syndrome of overeating that is marked by psychological distress. ${ }^{1}$ Binge eating is associated with impaired physical health and quality of life, ${ }^{2-4}$ and individuals with binge eating often have impaired psychological functioning, including high rates of comorbid psychological disorders. ${ }^{5-9}$ Estimates indicate that binge eating is a prevalent condition in both community and clinical samples.3,7,9,10 While much is known regarding the harmful impact of binge eating, knowledge of some psychological factors (e.g., anxiety) that may increase vulnerability to this behavior is limited.

The primary goal of this manuscript is to review and critically examine the role of anxiety in binge eating. We will begin by first briefly describing some relevant developments in defining binge eating. Next, we will highlight evidence-based models of binge eating behavior that include negative emotionality. Empirical evidence regarding comorbidity of anxiety and binge eating will be examined in relation to temporal risk and shared vulnerability factors. Finally, suggestions for the continued expansion of this area of study and clinical implications will be shared.

\section{Clinical and subclinical binge eating behaviors}

Binge eating episodes are often an indication of disordered eating; however, not all binge eating behavior occurs at a clinically significant level of severity.,11-13 Those who experience clinically significant, recurrent, episodes of binge eating in the absence of compensatory behaviors (e.g., vomiting, excessive exercise) may be assigned the diagnosis of Binge Eating Disorder (BED). This diagnosis is currently found in the criteria sets for further study of the Diagnostic and Statistical Manual of Mental Disorders, Version Four, Text Revision (DSM-IV-TR). ${ }^{1}$ For the purposes of clarity in this review, the term binge eating behavior (BEB) will be used to refer to repeated instances of binge eating episodes at the subclinical level that do not meet the definitional criteria for BED, while a single occasion will be referred to as a binge eating episode from herein.

Independent diagnostic criteria have been proposed for Binge Eating Disorder in the next revision of the DSM. ${ }^{14}$ Although the definition of a binge eating episode has not changed from the DSM-IV-TR, the criteria for BED are proposed to change in the DSM-V. In the proposed revision, BED may be diagnosed if recurrent episodes of binge eating occur in conjunction with three or more of the following: i) eating much more rapidly than normal, ii) eating until feeling uncomfortably full, iii) eating large amounts of food when not feeling physically hungry, iv) eating alone because of feeling embarrassed by how much one is eating, v) feeling disgusted with oneself, depressed, or very guilty after overeating. Additionally, marked distress regarding binge eating must be present, and the binge eating must occur, on average, at least once a week for 3 months, to meet criteria for clinical diagnosis.14 One clinical implication of this change may include an increase in the rate of diagnosis of BED. The DSM-IV-TR criteria require a more restrictive threshold for frequency and duration of binge eating disorder compared to the forthcoming DSM-IV criteria for binge eating disorder.1,14 Therefore, the change in the DSM criteria may impact the prevalence of BED.
Correspondence: Diane L. Rosenbaum, University of Missouri - Saint Louis, One University Boulevard, 325 Stadler Hall, St. Louis, M0, 63121, USA.

Tel. +1.314.516.4648 - Fax: +1.314.516.5392

E-mail:dlrf25@umsl.edu

Key words: binge eating, binge eating disorder, anxiety, depression, negative affect.

Contributions: both authors contributed substantially and meaningfully to the work presented here, including conceptualization and design. DR is primarily responsible for the drafting of the manuscript; KW provided critical revision of intellectual content.

Acknowledgements: the authors wish to thank Steven Bruce, Ph.D., Susan Kashubeck-West, Ph.D., and Zoe Peterson, Ph.D. for their contributions to this manuscript.

Conflict of interests: the authors declare no potential conflict of interests.

Received for publication: 30 November 2012.

Revision received: 3 January 2013.

Accepted for publication: 4 January 2013.

This work is licensed under a Creative Commons Attribution NonCommercial 3.0 License (CC BYNC 3.0).

(C) Copyright D.L. Rosenbaum and K.S. White., 2013

Licensee PAGEPress, Italy

Health Psychology Research 2013; 1:e19

doi:10.4082/hpr.2013.e19

\section{Theories of binge eating}

Several theories have been proposed to explain the development and maintenance of binge eating. The cognitive avoidance model stands out among theories that aid in understanding binge eating, particularly in its incorporation of negative emotionality. The strengths and weaknesses of binge eating theories will be discussed briefly.

\section{Perfectionism model}

The perfectionism model describes binge eating as a behavior that arises in response to an exacerbation of underlying precipitating factors, including depressive affect and perfectionism.15,16 The model is based on the assumption that binge eating is a short-term solution to reduce hunger (driven by dietary restraint) and improve mood (driven by depressive affect). It also posits a cyclical relation between triggers and binges whereby the same variables (e.g., depressive affect, dietary restraint) serve as both antecedents and con- 
sequences of a binge eating episode.16 Statistical tests of this model show that depressive affect does not consistently predict binge eating independent of other proposed triggers, however. 15

This model demonstrates utility; however, advanced examination of negative emotionality and binge eating may benefit from a more complete model. Inclusion of some of the psychological factors that characterize binge eating according to the DSM, such as loss of control, may strengthen a model of this nature. Additionally, the perfectionism model emphasizes the role of dietary restraint; however, this has not received consistent support as a hallmark feature of BED.16-19 Indeed, individuals with BED report negative affect (i.e., depression, anxiety) is a more likely trigger of binge eating episodes than hunger related to dietary restraint.17 Empirical evaluation of the perfectionism model does not support dietary restraint as an antecedent or consequence of binge eating. ${ }^{16}$ Additionally, it maybe limiting to propose cyclical maintenance processes as these do not adequately explain some of the biological, behavioral, and emotional factors, related to binge eating, such as weight gain and weight gain sequelae.

\section{Expectancy theory}

The principles of expectancy learning theory have been applied to help understand maladaptive eating behaviors. ${ }^{20,21}$ This theory suggests that the relation between specific eating behaviors, and the consequences that follow these behaviors, inform future eating behaviors. Specifically, in regard to binge eating, it has been suggested that individuals who engage in binge eating may do so as a result of a learned association between distress reduction and this behavior. ${ }^{20}$ Some research has supported that regulation of negative affect is an expectancy learned with binge eating. ${ }^{20,22-24}$ In at least one longitudinal study, the expectancy that eating helps to manage negative affect predicted binge eating. ${ }^{22}$

\section{Transdiagnostic model}

The transdiagnostic model of eating disorders has been proposed to explain maladaptive eating patterns, broadly. 25 The transdiagnostic model theorizes cognitive-behavioral processes including mood intolerance, low selfesteem, interpersonal difficulties, and perfectionism maintain eating disorders. ${ }^{26,27} \mathrm{~A}$ bidirectional relationship is proposed where antecedents of binge eating episodes also function as consequences. As implied by the name, this model was not developed to describe binge eating per se.25,26 and as such may be limited by the necessity for broad descriptions of eating pathology. To date, empirical evaluation of the transdiagnostic model has found mixed results regarding dis- order-specific differences in factors associated with eating disorders (e.g., dietary restraint, perfectionism, interpersonal difficulties), ${ }^{28,29}$ although transdiagnostic cognitive behavioral therapy appears to improve symptoms across eating disorder groups. ${ }^{30}$ This suggests an ideal binge eating model may include some transdiagnostic components, but also address factors specific to binge eating.

\section{Cognitive avoidance theory}

As suggested by the name, this conceptualization emphasizes binge eating as a method of cognitive avoidance. Cognitive avoidance is described as a process that limits the extent to which negative thoughts enter an individual's awareness to reduce negative emotions, such as anxiety. ${ }^{31}$ It has been suggested that binge eating serves as a method of cognitive avoidance, thereby aiding in anxiety reduction. ${ }^{31}$

There is evidence to support the notion that binge eating and cognitive avoidance are related, $, 2,33$ and specifically, that binge eating may function as a cognitive avoidance technique. ${ }^{34}$ Research has found that simplistic and rigid cognitive styles are common prior to a binge eating episode, 35 and that some report feelings of numbness or dissociation during a binge eating episode, 36,37 suggesting limited examination of the thoughts and feelings associated with this behavior. Additionally, there is support for the notion that negative affect (e.g., worry, guilt, anger) precedes binge eating as a trigger of this behavior.17,38-40 In fact, some have suggested that binge eating represents activation of an all or nothing cognitive style regarding intake, whereby maladaptive eating is more likely to occur in extremes. ${ }^{41}$ Cognitive-behavioral therapy, which facilitates an examination of thoughts and challenges cognitive avoidance, has demonstrated success among individuals with binge eating. $25,30,42,43$

Some have explained binge eating as cognitive avoidance using an escape from awareness model. ${ }^{44}$ This model suggests when individuals attribute a loss of control over eating to internal, stable, and global factors, binge eating episodes are more likely to be repeated. 41 The time between binge eating episodes may also be reduced if the above-mentioned attributions are present. Moreover, the emotional sequelae (e.g., depression and guilt) may increase vulnerability to additional binge eating episodes. ${ }^{44}$ In order to reduce the salience of negative affect, individuals may engage in a process of cognitive narrowing during binge eating. That is, the processing of actions and stimuli take place on a low-level, concrete, spectrum; the long-range consequences of binge eating are kept outside of awareness in favor of a limited interpretation of the direct events. ${ }^{44}$

There is empirical support for the escape model. ${ }^{45,46}$ As some have noted however, often binge eating does not result in the desired improvement in emotional state. ${ }^{17}$ In fact, many individuals experience worsened negative affect after engaging in binge eating. 17,41,47,48 Some previous examinations of temporal binge eating patterns have evaluated negative affect broadly, without distinguishing between emotional components (e.g., anxiety, depression). ${ }^{17,47,49}$ It may be that binge eating is successful in reducing some emotional components of negative affect (i.e., anxiety) but may exacerbate others (i.e., depression) associated with BED, supporting a trade off theory of affect regulation. ${ }^{40}$ Previous research conducted among individuals with BN suggests distinct roles for anxiety and depression in the binge-purge cycle,50-52 however published manuscripts regarding the specific temporal roles of anxiety and depression within the context of BED are largely absent from the literature. Examining the temporal relations between the emotional components of negative affect and the course of binge eating behavior may advance our understanding of binge eating.

There are some elements of the original escape model that may limit its application to BED. The original model was developed for binge eating within the context of BN and suggests a drive for thinness motivates dysfunctional eating. ${ }^{44}$ This may be inappropriate to describe binge eating within the context of BED. Some have also suggested that rather than facilitating cognitive avoidance, binge eating actually facilitates increased negative self-evaluation. 53

In sum, several theories have been proposed to explain binge eating. In general, most empirically supported theories of binge eating suggest that binge eating episodes occur in response to distressing affective states. $15,20,26,44$ It may be that binge eating is successful in facilitating avoidance of the painful negative emotions that triggered the binge eating episode, such as anxiety, during the process of consumption but increases the risk for a different type of negative emotionality following consumption, such as depression. Additional study is needed to clarify the ways in which negative emotionality and cognitive avoidance impact the process of binge eating.

\section{Anxiety and binge eating theory}

Previous research has been useful in increasing the understanding of the relation of binge eating with some components of negative affect (i.e., depression); however, the current literature under-represents the contributions of anxiety, and is therefore in need of further development. The cue for expansion may 
be taken from the text of the DSM-IV-TR, which indicates that binge eating episodes may be triggered by a variety of dysphoric states, and names anxiety as an example of this type of antecedent. ${ }^{1}$ In addition, research has suggested binge eating may serve as a method by which some individuals cope with anxiety. ${ }^{4,55}$ This has been supported by research that demonstrates this behavior is associated with a reduction in anxiety. 56 Therefore, models that incorporate the roles of both depression and anxiety may provide a more comprehensive understanding of binge eating. We suggest that a model that includes several of the negative emotional components of negative affect, perhaps serving in discrete roles, may best predict binge eating and its associated features. Further, adoption of the phrase binge eating process rather than binge eating cycle may promote consideration of the variability between emotional antecedents and emotional consequences.

Cognitive Avoidance Theory supports the role of anxiety in the binge eating process by suggesting that individuals engage in binge eating episodes in order to escape from this state. ${ }^{44} \mathrm{~A}$ variety of factors may contribute to the development of anxiety prior to a binge eating episode. Environmental factors such as stressful life events and socio-cultural expectations may increase vulnerability for anxiety. That is, environmental factors may contribute to elevations in perceived stress and decreases in perceived control, both of which have been linked to manifestations of anxiety.57-59 Additional research is needed to investigate other factors that may increase vulnerability to anxiety and binge eating.

\section{Binge eating and psychological functioning}

Individuals who exhibit binge eating also demonstrate impaired psychological functioning; however, the relation between psychological functioning and binge eating is complex. The relative risks of psychiatric impairment are raised for those who engage in binge eating compared to those who do not.3,60 Epidemiologic study indicates that binge eating is associated with a high rate of Axis I symptoms, Axis II symptoms, and undifferentiated psychological impairment. ${ }^{5}$ Some studies that controlled for obesity have found that BED is associated greater psychiatric impairment than BEB.6,61,62 Similarly, psychiatric comorbidity has generally been associated with greater binge eating symptom severity (e.g., more frequent binge eating episodes), 63 however even subclinical binge eating is associated with elevations in psychiatric symptoms. ${ }^{64,65}$
Axis I disorders co-occur at a high rate for individuals who engage in clinically significant binge eating. Approximately $74-79 \%$ of individuals with BED have been diagnosed with another Axis I disorder in their lifetime..$^{7,8}$ Some estimates suggest lifetime rates of mood disorders (i.e., 54-61\%) are somewhat more common than anxiety disorders (i.e., 29$37 \%) ;, 86$ however, others have found higher rates of lifetime anxiety disorders (i.e., 65\%) than mood disorders (i.e., 46\%) among individuals with BED.7 The rates at which individuals with BED experience current mood and anxiety disorders are somewhat comparable, estimated as $26 \%$ and $25 \%$, respectively. 8 The rates of comorbid anxiety and mood disorders among individuals with BED are similar across sexes. 67

While less is known about comorbidities of $\mathrm{BEB}$, research indicates co-occurring impairments may resemble the prevalence rates of disorders associated with BED. Research suggests approximately $64-77 \%$ of individuals with BEB have met criteria for an Axis I diagnosis. ${ }^{7}$ In regard to specific diagnoses, lifetime prevalence rates of major depression, panic disorder, borderline personality disorder, and avoidant personality disorder are greater among individuals with BEB than those without, after controlling for obesity. 60 Among individuals with $\mathrm{BEB}$, the rate of lifetime anxiety disorders range from $40-60 \%$ while the rate of lifetime mood disorders range from $28-44 \%{ }^{7}$ Current mood and anxiety disorders are also more prevalent among individuals with BEB than those without.6,65 Some prevalence estimates have indicated as many as $63 \%$ of individuals with $B E B$ meet criteria for at least one comorbid anxiety disorder. ${ }^{68}$ Moreover, examinations of specific current anxiety and mood disorders among individuals with BEB have approximated that major depressive disorder occurs at $46 \%$, generalized anxiety disorder occurs at $13 \%$, social phobia occurs at $22 \%$, and specific phobia occurs at $28 \%{ }^{6}$

Much research has focused on depressive disorders in the binge eating literature. Empirical research has found a linear relation between depressive symptoms and severity of binge eating, ${ }^{69,70}$ and an elevated prevalence of depression in those with BED. ${ }^{60,71-73}$ Some have suggested that depression may function as a maintenance factor associated with binge eating; 70 however, additional research is needed to support this claim. In fact, perhaps because research has supported the notion that major depression is the most frequent comorbidity of BED, $6,8,66$ some have called for BED treatments to address negative mood in order to increase their efficacy.66 To date, few studies have examined the linear impact of depression treatment on binge eating. A metaanalysis of the binge eating treatment literature has not supported a significant relation between improvement in binge eating and improvement in depressive symptoms. ${ }^{74}$

Expanding investigations of psychological comorbidities to include other forms of negative emotionality may be an important next step in the understanding of development and maintenance of binge eating. That is, while it is advantageous to recognize the role of depression in binge eating, it is important to ensure that other avenues of investigation regarding negative emotionality are also encouraged within the literature. Indeed, research has supported the notion that other forms of negative emotionality, such as anxiety, have demonstrated a similar relation to binge eating as depression. ${ }^{73}$ Perhaps the existing literature regarding depression and binge eating may serve as a springboard for the development of a broader framework for negative emotionality research within binge eating that features anxiety.

\section{Anxiety and binge eating}

Evidence suggests that disordered eating is strongly associated with anxiety. The rate of comorbidity between BED and anxiety disorder diagnoses is high, with a lifetime prevalence of $37 \% .8$ Anxiety disorders are the second most common psychological comorbidity among individuals with BED and the morbidly obese. 8,75 There are elevated odds for generalized anxiety disorder and panic disorder among individuals with BED based on community estimates. ${ }^{3}$ Moreover, individuals with a history of eating disorders, but without current clinically significant impairment, tend to exhibit an anxious personality style, even in the absence of a lifetime history of a clinically significant anxiety disorder. ${ }^{76}$ Recently, increased scholarly attention has helped to increase awareness of some factors that may be important in the broader relation between anxiety and binge eating.

\section{Anxiety sensitivity and binge eating}

A growing body of empirical literature suggests anxiety sensitivity, a cognitive style in which anxiety-related physiological arousal is interpreted as dangerous, ${ }^{77,78}$ may be important in the relation between anxiety and binge eating. Notably, individuals with high anxiety sensitivity also have an increased propensity toward negative affect,78,79 which has previously been highlighted as a primary component in binge eating theory.15,20,26,44 Extrapolating from the well-established rela- 
tion between anxiety sensitivity and drug and alcohol use, ${ }^{80-85}$ some have proposed that as a behavioral emotion regulation strategy, binge eating may be used to cope with the psychological discomfort associated with the expression of anxiety sensitivity. 86

Evidence supports a tendency among those with high anxiety sensitivity to believe that eating can function as a tool to regulate affect; they are more likely to express an urge to eat when experiencing negative affect. ${ }^{87}$ Empirical study has also found the relation between anxiety sensitivity and binge eating exists independent of symptoms of depression and anxiety. 88 Research has also suggested that distress tolerance and experiential avoidance serve as mediators in the relation between anxiety sensitivity and disordered eating. ${ }^{89,90}$ Taken together, these findings support the notion that binge eating may be particularly likely to serve as a behavioral avoidance coping strategy for those with anxiety sensitivity and low tolerance for negative affect. Interestingly, research suggests that individuals with high anxiety sensitivity who engage in alternative negative affect reduction behaviors, such as physical activity, experience less binge eating. ${ }^{86}$ This suggests that treatments that facilitate the reduction of negative affect through more healthful means may be effective in reducing binge eating among individuals with high anxiety sensitivity. Additional research is needed to understand the role that distress tolerance techniques may have in treating binge eating within the context of anxiety sensitivity. Moreover, longitudinal research, particularly within the context of BED, is needed in order to determine whether anxiety sensitivity may function as a risk factor, or correlate, of binge eating.

\section{Development and maintenance of anxiety and binge eating}

A longstanding relationship exists between binge eating and anxiety. Individuals with binge eating report higher rates of anxiety than those without binge eating, after controlling for obesity. 60,61 Further, individuals who have engaged in binge eating episodes are approximately 1.7 times more likely to report anxiety than those who have not. ${ }^{5}$ In order to explain the high rates of comorbidity observed between anxiety and binge eating, some have proposed that i) anxiety may occur secondary to an eating disorder, ii) anxiety may serve as a risk factor for eating disorders, or iii) comorbid eating and anxiety disorders may occur as a result of shared vulnerability factors. ${ }^{91}$ Empirical evidence favors the latter two of these potential links.

\section{Temporal risk}

\section{Anxiety secondary to binge eating}

While research generally supports the development of binge eating after or at the same time as anxiety, there is some evidence to suggest anxiety may develop secondary to binge eating. For example, in a longitudinal study, baseline BEB predicted anxiety, although not depression, approximately five years later, according to a model that controlled for baseline anxiety and covariates. ${ }^{92}$ Some genetic data have supported that individuals with BEB are at an increased risk for symptoms of anxiety, independent of BMI. ${ }^{93}$

\section{Anxiety as a risk factor for binge eating}

Anxiety has been noted as a risk factor for a variety of disordered eating patterns, including binge eating, ${ }^{94}$ due to its frequent onset prior to maladaptive eating behaviors. ${ }^{31}$ Retrospective research has found that anxiety disorders typically precede eating disorder diagnoses, with anxiety disorders originating in childhood in many cases. ${ }^{76} \mathrm{In}$ fact, at least half of women who are diagnosed with an eating disorder have a history of prior diagnosis with an anxiety disorder. Over $70 \%$ of these participants experienced an anxiety disorder either before or after the onset of the eating disorder.91 Additional research is needed to clarify the temporal risk that anxiety may pose for binge eating.

\section{Shared vulnerability factors}

The literature suggests that binge eating and anxiety may be related though shared vulnerability factors. ${ }^{91}$ Distal (e.g., childhood) and proximal experiences of stress have been shown to impact the development of anxiety and binge eating. In regard to childhood stressors, teasing and bullying have been shown to function as vulnerability factors for both anxiety and eating disorders. ${ }^{31}$ Proximal factors, such as recent experiences of perceived stress or stressful life events, ${ }^{95-99}$ may also relate to the development of both anxiety and eating disorders. Research suggests a shared course for emotional distress and features of binge eating. That is, empirical evidence supports that loss of control in relation to eating may be a persistent condition that develops in childhood and extends through adolescence. ${ }^{92}$ Studies have also suggested a shared genetic vulnerability for both anxiety and eating disorders. ${ }^{100}$ Indeed, the prevalence of anxiety disorders is greater among first degree relatives of individuals with BED than among controls, ${ }^{101}$ suggesting a developmental vulnerability. It is important to continue to expand research efforts to include investigations of vulnerabilities to BED as shifts in our diagnostic system may be on the horizon with DSM-V.

\section{Shared maintenance factors}

In addition to overlapping developmental pathways, anxiety and binge eating may also share similar maintenance factors and patterns of symptom expression. For instance, individuals with disordered eating and anxiety may share similar maladaptive cognitive patterns. ${ }^{31}$ Some suggest that cognitive patterns that emphasize worry influence the maintenance of both anxiety and eating disorders. ${ }^{102,103}$ This is supported by research that found that levels of worry are similar between individuals with eating and anxiety disorders. ${ }^{104}$ Binge eating may also be considered by some to be a compulsive behavior designed to reduce distress. ${ }^{31}$ Indeed, it may be that binge eating may function as a type of selfsoothing behavior similar to other oral adjunctive behaviors that have been linked to anxiety, such as teeth clenching/grinding, or nail-biting. ${ }^{105,106}$

\section{Discussion}

This review has presented an overview binge eating theories, and the ways in which anxiety is relevant as a component of negative affect in these models. In addition, this review has demonstrated that anxiety is a common comorbidity of clinical and subclinical binge eating, and has presented evidence for a variety of mechanisms through which they may be related. We conclude with our thoughts regarding continued investigation of this topic, and related clinical implications.

\section{Areas for expansion of empirical research}

The empirical research on binge eating and anxiety has offered valuable contributions to the understanding of this area; however, there are limitations which future research may work to remedy. One area for growth concerns the linearity of the relation of between binge eating and anxiety. To date, the published literature has not explored whether the severity of anxiety and the severity of binge eating may be related. Additionally, temporal concerns are also relevant, as it remains unknown whether the severity of anxiety predicts severity of binge eating symptoms. Further, because much of the research in this area has examined comorbidity among clinical disorders, it is unknown whether clinically significant anxiety disorders predict subclinical binge eating. The proposed revision to include BED as an independent eating disorder diagnosis is evidence that classification systems are malleable. Our 
understanding of binge eating and anxiety may benefit from broadening our scope beyond dichotomies to better understand severity and variability of symptoms. We recommend subclinical symptoms of anxiety, and anxiety sensitivity, should also be examined in their relation to the development and maintenance of binge eating.

The literature regarding binge eating and anxiety is young and burgeoning. It may be expected that after the adoption of BED as an independent clinical diagnosis the literature will continue to expand and incorporate additional investigations of the impact of anxiety on the course and severity of binge eating. Therefore, we believe the future of binge eating research is bright. Avenues for investigation include examinations of factors that influence the progression of subclinical behaviors to clinically significant binge eating, and the impact of early anxiety-focused interventions on binge eating. The clinical implications of future research regarding anxiety and binge eating warrant further discussion.

\section{Clinical implications}

There are clinical implications that bear on the discussion of future research regarding binge eating and anxiety. As previously mentioned, there is a need for continued investigation of anxiety and binge eating from a dimensional perspective that includes subclinical expressions of these disorders. In particular, the course of both clinical and subclinical binge eating, and the ways in which anxiety and other facets of negative emotionality impact the course of binge eating, remain poorly understood. Further, the extent to which clinical resources may benefit individuals with subclinical binge eating is unknown. This may be a focus of future research regarding differential impairments in quality of life among individuals with binge eating.

Protective factors that limit the progression of subclinical BEB to a clinically significant eating disorder warrant additional study. Although several theories have been proposed to understand the factors that contribute to the development and maintenance of binge eating, $15,20,26,44$ investigations of prevention efforts targeting psychological vulnerability factors are largely missing from the literature. Empirical tests of factors related to risk and resilience may strengthen prevention efforts. Given the potential impact of multicultural factors on binge eating, investigation of protective factors, in regard to negative emotionality, should be relevant to diverse populations.

Some constituent features of anxiety may be may be important in the expression and persistence of binge eating. Future work examining behavioral avoidance of anxiety in binge eating may be influential in this area. Behavioral avoidance is a hallmark feature of anxiety; 107 patients with binge eating may show a similar pattern of behavioral avoidance in eating and anxiety. In other words, individuals may engage in binge eating to mitigate (or avoid, distract) themselves from symptoms of anxiety; 31 in turn, use of binge eating may lead to a short-term alleviation of anxiety symptoms but contribute to maintained or increased anxiety over time within BEB and BED. This may have clinical implications, including modifications and advancements to existing binge eating treatments to address behavioral avoidance and increase distress tolerance.

Because reliance on binge eating may minimize opportunities for learning effective longterm coping strategies for anxiety, individuals engaged in this cycle may develop worries or negative core beliefs regarding their ability to control negative moods, or cope with life stressors, without binge eating. Similarly, depression may worsen with weight gain and obesityrelated health impairments associated with long-term binge eating. Binge eating treatments that address the importance of associated emotional factors may be most effective. That is, comprehensive treatments should address the psychological antecedents and consequences of this behavior as these are of critical importance to the syndromal nature of binge eating. While specific research addressing relapse prevention is limited, interventions that address negative emotionality and related psychological factors may be most successful in long-term binge eating treatment. In addition, supplemental treatment for anxiety may help extend remission rates and enhance quality of life among individuals who have already been successful responders to binge eating treatments. Efforts designed to improve resilience to binge eating are also less prevalent in the current literature. As such, future clinical endeavors may be informed by these avenues and emerging data.

\section{Conclusions}

In sum, anxiety is an important factor in the development and maintenance of binge eating that has been somewhat overlooked in the literature. This review argues that anxiety is a critical component in the application of empirically supported binge eating theory. This is supported by the body of previous research that illustrates not only a high co-occurrence of anxiety and binge eating symptoms, but also the ways in which anxiety may serve a unique role in the development and maintenance of binge eating syndrome. Examinations of depression and binge eating will likely yield significant associations; however, we recommend an expansion of the literature regarding negative affect and binge eating to include more research to enhance the understanding of the contributions of anxiety. With the introduction of the revised diagnostic criteria for BED comes an opportunity to put forth innovative research to improve the conceptualization of discrete roles of the components of negative affect that impact this disorder. In conclusion, the existing literature provides strong support for anxiety as a key factor in binge eating and invites the inclusion of anxiety in future clinical binge eating research.

\section{References}

1. American Psychiatric Assocation. Diagnostic and statistical manual of mental disorders: DSM-IV-TR. Washington DC: American Psychiatric Association; 2000.

2. Kolotkin R, Westman E, Ostby T, et al. Does binge eating disorder impact weight-related quality of life? Obesity 2004;12:999-1005.

3. Grucza RA, Przybeck TR, Cloninger CR. Prevalence and correlates of binge eating disorder in a community sample. Compr Psychiat 2007;48:124-31.

4. Masheb RM, Grilo C. Quality of life in patients with binge eating disorder. Eat Weight Disord 2004;9:194-9.

5. Bulik CM, Sullivan PF, Kendler KS. Medical and psychiatric morbidity in obese women with and without binge eating. Int J Eat Disord 2002;32:72-8.

6. Javaras KN, Pope Jr. HG, Lalonde JK, et al. Co-occurence of binge eating disorder with psychiatric and medical disorders. J Clin Psychiat 2008;69:266-73.

7. Hudson JI, Hiripi E, Pope Jr HG, Kessler RC. The prevalence and correlates of eating disorders in the national comorbidity survey replication. Biol Psychiat 2007;61: 348-58.

8. Grilo CM, White MA, Masheb RM. DSM-IV psychiatric disorder comborbidity and its correlates in binge eating disorder. Int $\mathrm{J}$ Eat Disord 2009;42:228-34.

9. Spitzer RL, Devlin M, Walsh BT, et al. Binge eating disorder: a multisite field trial of the diagnostic criteria. Int $\mathrm{J}$ Eat Disord 1992;11:191-203.

10. Grilo CM. Binge eating disorder. In: Fairburn CG, Brownell KD, eds. Eating disorders and obesity: a comprehensive handbook. 2nd edition. New York: Guilford Press; 2002. pp 178-182.

11. Kinzl JF, Traweger C, Trefalt E, et al. Binge eating disorder in females: a population-based investigation. Int $\mathrm{J}$ Eat Disord 1999;25:287-92.

12. Striegel-Moore RH, Perrin N, DeBar L, et 
al. Screening for binge eating disorders using the patient health questionnaire in a community sample. Int $\mathrm{J}$ Eat Disord 2010;43:337-43.

13. Touchette E, Henegar A, Godart NT, et al. Subclinical eating disorders and their comorbidity with mood and anxiety disorders in adolescent girls. Psychiatry Res 2011;185:185-92.

14. American Psychiatric Assocation. DSM-5 development website. Available from: http://www.dsm5.org/. Accessed on: May 2011.

15. Sherry SB, Hall PA. The perfectionism model of binge eating: tests of an integrative model. J Pers Soc Psychol 2009;96: 690-709.

16. Mackinnon SP, Sherry SB, Graham AR, et al. Reformulating and testing the perfectionism model of binge eating among undergraduate women: a short-term, three-wave longitudinal study. J Couns Psychol 2011;58:630-46.

17. Stein RI, Kenardy J, Wiseman CV, et al. What's driving the binge in binge eating disorder?: A prospective examination of precursors and consequences. Int $\mathrm{J}$ Eat Disord 2007;40:195-203.

18. Williamson DA, Martin CK, Anton SD, et al. Is caloric restriction associated with development of eating-disorder symptoms? Results from the CALERIE trial. Health Psychol 2008;27 Suppl 1:S32-S42.

19. Blomquist KK, Grilo CM. Predictive significance of changes in dietary restraint in obese patients with binge eating disorder during treatment. Int $\mathrm{J}$ Eat Disord 2011;44: 515-23.

20. Hohlstein LA, Smith GT, Atlas JG. An application of expectancy theory to eating disorders: development and validation of measures of eating and dieting expectancies. Psychol Assessment 1998;10:49-58.

21. Combs JL, Pearson CM, Smith GT. A risk model for preadolescent disordered eating. Int J Eat Disord 2011;44:596-604.

22. Combs JL, Smith GT, Simmons JR. Distinctions between two expectancies in the prediction of maladaptive eating behavior. Pers Indiv Differ 2011;50:25-30.

23. Fischer S, Smith GT. Binge eating, problem drinking, and pathological gambling: Linking behavior to shared traits and social learning. Pers Indiv Differ 2008;44: 789-800.

24. Smith GT, Simmons JR, Flory K, et al. Thinness and eating expectancies predict subsequent binge-eating and purging behavior among adolescent girls. J Abnorm Psychol 2007;116:188-97.

25. Fairburn CG, Cooper Z, Shafran R. Cognitive behaviour therapy for eating disorders: a transdiagnostic theory and treatment. Behav Res Ther 2003;41:509-28.
26. Fairburn CG. Eating disorders: the transdiagnostic view and the cognitive behavioral theory. In: Fairburn CG, ed. Cognitive behavior therapy and eating disorders. New York: Guilford Press; 2008. pp 7-22.

27. Cooper Z, Fairburn CG. The evolution of enhanced cognitive behavior therapy for eating disorders: learning from treatment nonresponse. Cogn Behav Pract 2011;18:394-402.

28. Lampard AM, Tasca GA, Balfour L, Bissada $H$. An evaluation of the transdiagnostic cognitive-behavioural model of eating disorders. Eur Eat Disord Rev 2012 [in press].

29. Hoiles KJ, Egan SJ, Kane RT. The validity of the transdiagnostic cognitive behavioural model of eating disorders in predicting dietary restraint. Eat Behav 2012;13:123-6.

30. Fairburn CG, Cooper Z, Doll HA, et al. Transdiagnostic cognitive-behavioral therapy for patients with eating disorders: a two-site trial with 60-week followup. Am J Psychiatry 2009;166:311-9.

31. Pallister E, Waller G. Anxiety in the eating disorders: understanding the overlap. Clin Psychol Rev 2008;28:366-86.

32. Meyer C, Serpell L, Waller G, et al. Cognitive avoidance in the strategic processing of ego threats among eating-disordered patients. Int J Eat Disord 2005;38: 30-6.

33. Sulkowski ML, Dempsey J, Dempsey AG. Effects of stress and coping on binge eating in female college students. Eat Behav 2011;12:188-91.

34. Davis KR, Fischer S. The influence of trait anger, trait anxiety and negative urgency on disordered eating. Pers Indiv Differ 2013;54:307-10.

35. Lingswiler VM, Crowther JH, Stephens MAP. Affective and cognitive antecedents to eating episodes in bulimia and binge eating. Int J Eat Disord 1989;8:533-9.

36. Paxton SJ, Diggens J. Avoidance coping, binge eating, and depression: an examination of the escape theory of binge eating. Int J Eat Disorder 1997;22.

37. McShane JM, Zirkel S. Dissociation in the binge-purge cycle of bulimia nervosa. J Trauma Dissociation 2008;9:463-79.

38. Stickney MI, Miltenberger RG, Wolff G. A descriptive analysis of factors contributing to binge eating. $\mathrm{J}$ Behav Ther Experiment Psychiatry 1999;30:177-89.

39. Napolitano MA, Himes S. Race, weight, and correlates of binge eating in female college students. Eat Behav 2011;12:2936 .

40. Kenardy J, Arnow B, Agras WS. The aversiveness of specific emotional states associated with binge-eating in obese subjects. Aust NZ J Psychiatry 1996;30: $839-44$.

41. Grilo CM, Shiffman S. Longitudinal investigation of the abstinence violation effect in binge eaters. $\mathrm{J}$ Consult Clin Psychol 1994:62:611-9.

42. Lynch FL, Striegel-Moore RH, Dickerson JF, et al. Cost-effectiveness of guided selfhelp treatment for recurrent binge eating. J Consult Clin Psychol 2010;78:322-33.

43. Brownley KA, Berkman ND, Sedway JA, et al. Binge eating disorder treatment: a systematic review of randomized controlled trials. Int J Eat Disord 2007;40:337-48.

44. Heatherton TF, Baumeister RF. Binge eating as escape from self-awareness. Psychol Bull 1991;110:86-108.

45. Engelberg MJ, Steiger H, Gauvin L, Wonderlich SA. Binge antecedents in bulimic syndromes: an examination of dissociation and negative affect. Int J Eat Disord 2007;40:531-6.

46. Blackburn S, Johnston L, Blampied N, et al. An application of escape theory to binge eating. Eur Eat Disord Rev 2006;14: 23-31.

47. Goldschmidt AB, Engel SG, Wonderlich SA, et al. Momentary affect surrounding loss of control and overeating in obese adults with and without binge eating disorder. Obesity 2012;20:1206-11.

48. Haedt-Matt AA, Keel PK. Revisiting the affect regulation model of binge eating: $A$ meta-analysis of studies using ecological momentary assessment. Psychol Bull 2011;137:660-81.

49. Pollert GA, Engel SG, Schreiber-Gregory DN, et al. The role of eating and emotion in binge eating disorder and loss of control eating. Int J Eat Disord 2013;46:233-8.

50. Hetherington MM, Altemus M, Nelson ML, et al. Eating behavior in bulimia nervosa: multiple meal analyses. Am J Clin Nutr 1994;60:864-73.

51. Kaye WH, Gwirtsman HE, George DT, et al. Relationship of mood alterations to bingeing behaviour in bulimia. $\mathrm{Br} \mathrm{J}$ Psychiatry 1986;149:479-85.

52. Elmore DK, de Castro JM. Self-rated moods and hunger in relation to spontaneous eating behavior in bulimics, recovered bulimics, and normals. Int $\mathrm{J}$ Eat Disord 1990;9:179-90.

53. Nolen-Hoeksema S, Stice E, Wade E, Bohon C. Reciprocal relations between rumination and bulimic, substance abuse and depressive symptoms in female adolescents. J Abnorm Psychol 2007;116:198-207.

54. Binford RB, Mussell MP, Peterson CB, et al. Relation of binge eating age of onset to functional aspects of binge eating in binge eating disorder. Int $\mathrm{J}$ Eat Disord 2004;35:286-92.

55. Mitchell JE, Mussell MP, Peterson CB, et 
al. Hedonics of binge eating in women with bulimia nervosa and binge eating disorder. Int J Eat Disord 1999;26:165-70.

56. Fairburn CG, Cooper Z, Cooper PJ. The clinical features and maintenance of bulimia nervosa. In: Brownell KD, Foreyt JP, eds. Handbook of eating disorders: physiology, psychology and treatment of obesity, anorexia and bulimia. New York: Basic Books; 1986. pp 389-404.

57. Bergdahl J, Bergdahl M. Perceived stress in adults: prevalence and association of depression, anxiety and medication in a Swedish population. Stress Health 2002;18:235-41.

58. Rapee RM, Craske MG, Brown TA, Barlow DH. Measurement of perceived control over anxiety-related events. Behav Ther 1996;27:279-93.

59. Sanderson WC, Rapee RM, Barlow DH. The influence of an illusion of control on panic attacks induced via inhalation of 5.5\% carbon-dioxide-enriched air. Arch Gen Psychiatry 1989;46:157-62.

60. Yanovski SZ, Nelson JE, Dubbert BK, Spitzer RL. Association of binge eating disorder and psychiatric comorbidity in obese subjects. Am J Psychiatry 1993;150: 1472-9.

61. Mussell MP, Mitchell JE, De Zwaan M, et al. Clinical characteristics associated with binge eating in obese females: a descriptive study. Int J Obesity 1996;20: 324-31.

62. de Zwaan M, Mitchell JE, Seim HC, et al. Eating Related and general psychopathology in obese females with binge eating disorder. Int J Eat Disord 1994;15:43-52.

63. Spindler A, Milos G. Links between eating disorder symptom severity and psychiatric comorbidity. Eat Behav 2007;8:36473.

64. Striegel-Moore RH, Wilfley D, Pike KM, et al. Recurrent binge eating in black american women. Arch Fam Med 2000;9:83-7.

65. Reichborn-Kjennerud T, Bulik CM, Sullivan PF, et al. Psychiatric and medical symptoms in binge eating in the absence of compensatory behaviors. Obesity Res 2004:12:1445-54.

66. Wilfley DE, Friedman MA, Dounchis JZ, et al. Comorbid psychopathology in binge eating disorder: relation to eating disorder severity at baseline and following treatment. J Consult Clin Psychol 2000; 68:641-9.

67. Guerdjikova AI, McElroy SL, Kotwal R, Keck Jr PE. Comparison of obese men and women with binge eating disorder seeking weight management. Eat Weight Disord 2007;12:19-23.

68. Schwalberg MD, Barlow DH, Alger SA, Howard LJ. Comparison of bulimics, obese binge eaters, social phobics, and individuals with panic disorder on comorbidity across DSM-III anxiety disorders. J Abnorm Psychol 1992;101:675-81.

69. Azarbad L, Corsica J, Hall B, Hood M. Psychosocial correlates of binge eating in Hispanic, African American, and Caucasian women presenting for bariatric surgery. Eat Behav 2010;11:7984 .

70. Mazzeo SE, Saunders R, Mitchell KS. Gender and binge eating among bariatric surgery candidates. Eat Behav 2006;7:4752.

71. Smith DE, Marcus MD, Lewis CE, et al. Prevalence of binge eating disorder, obesity, and depression in a biracial cohort of young adults. Ann Behav Med 1998;20:227-32.

72. Telch CF, Stice E. Psychiatric comorbidity in women with binge eating disorder: Prevalence rates from a non-treatmentseeking sample. J Consult Clin Psychol 1998;66:768-76.

73. Pinaquy $\mathrm{S}$, Chabrol $\mathrm{H}$, Simon $\mathrm{C}$, et al. Emotional eating, alexithymia, and bingeeating disorder in obese women. Obesity Res 2003;11:195-201.

74. Vocks S, Tuschen-Caffier B, Pietrowsky R, et al. Meta-analysis of the effectiveness of psychological and pharmacological treatments for binge eating disorder. Int J Eat Disord 2010;43:205-17.

75. van Hout GCM, van Oudheusden I, van Heck GL. Psychological profile of the morbidly obese. Obesity Surg 2004;14:579-88.

76. Kaye WH, Bulik CM, Thornton L, et al. Comorbidity of anxiety disorders with anorexia and bulimia nervosa. Am J Psychiatry 2004;161:2215-21.

77. Reiss S. Expectancy model of fear, anxiety, and panic. Clin Psychol Rev 1991;11: 141-53.

78. Taylor S. Anxiety sensitivity: theoretical perspectives and recent findings. Behav Res Ther 1995;33:243-58.

79. Otto MW, Pollack MH, Fava M, et al. Elevated anxiety sensitivity index scores in patients with major depression: correlates and changes with antidepressant treatment. J Anxiety Disord 1995;9:11723.

80. Lejuez CW, Paulson A, Daughters SB, et al. The association between heroin use and anxiety sensitivity among inner-city individuals in residential drug use treatment. Behav Res Ther 2006;44:667-77.

81. Zvolensky MJ, Feldner MT, Leen-Feldner E, et al. Evaluating the role of anxiety sensitivity in smoking outcome expectancies among regular smokers. Cogn Ther Res 2004;28:473-86.

82. Zvolensky MJ, Leen-Feldner EW. Anxiety and stress vulnerability and substance problems: theory, empirical evidence, and directions for future research. Clin Psychol Rev 2005;25:707-12.

83. DeHaas RA, Calamari JE, Bair JP, Martin ED. Anxiety sensitivity and drug or alcohol use in individuals with anxiety and substance use disorders. Addict Behav 2001;26:787-801.

84. Evatt DP, Kassel JD. Smoking, arousal, and affect: the role of anxiety sensitivity. J Anxiety Disord 2010;24:114-23.

85. DeMartini KS, Carey KB. The role of anx iety sensitivity and drinking motives in predicting alcohol use: a critical review. Clin Psychol Rev 2011;31:169-77.

86. DeBoer LB, Tart CD, Presnell KE, et al. Physical activity as a moderator of the association between anxiety sensitivity and binge eating. Eat Behav 2012;13:194 201.

87. Hearon BA, Utschig AC, Smits JAJ, et al. The role of anxiety sensitivity and eating expectancy in maladaptive eating behavior. Cogn Ther Res 2012. [In press].

88. Anestis MD, Holm-Denoma JM, Gordon $\mathrm{KH}$, et al. The role of anxiety sensitivity in eating pathology. Cogn Ther Res 2008;32: 370-85.

89. Anestis MD, Selby EA, Fink EL, Joiner TE The multifaceted role of distress tolerance in dysregulated eating behaviors. Int J Eat Disord 2007;40:718-26.

90. Fulton JJ, Lavender JM, Tull MT, et al. The relationship between anxiety sensitivity and disordered eating: the mediating role of experiential avoidance. Eat Behav 2012;13:166-9.

91. Godart NT, Flament MF, Curt F, et al. Anxiety disorders in subjects seeking treatment for eating disorders: a DSM-IV controlled study. Psychiatry Res 2003;117: 245-58.

92. Tanofsky-Kraff M, Shomaker LB, Olsen C, et al. A prospective study of pediatric loss of control eating and psychological outcomes. J Abnorm Psychol 2011;120:108 18.

93. Reichborn-Kjennerud T, Bulik CM, Tambs $\mathrm{K}$, Harris JR. Genetic and environmental influences on binge eating in the absence of compensatory behaviors: a populationbased twin study. Int $\mathrm{J}$ Eat Disord 2004;36:307-14.

94. Bulik CM, Sullivan PF, Carter FA, Joyce PR. Lifetime anxiety disorders in women with bulimia nervosa. Compr Psychiatry 1996;37:368-74.

95. McLaren S, Crowe SF. The contribution of perceived control of stressful life events and thought suppression to the symptoms of obsessive-compulsive disorder in both non-clinical and clinical samples. Anxiety Disord 2003;17:389-403.

96. Netter P, Croes S, Merz P, Muller,M. Emotional and cortisol response to 
uncontrollable stress. In: Spielberger CD, Sarason IG, eds. Stress and anxiety. New York: Hemisphere Publishing Corporation; 1991.

97. Striegel-Moore RH, Dohm F, Kraemer HC, et al. Risk factors for binge-eating disorders: an exploratory study. Int J Eat Disord 2007;40:481-7.

98. Gluck ME. Stress response and binge eating disorder. Appetite 2006;46:26-30.

99. Loth K, van den Berg P, Eisenberg ME, Neumark-Sztainer D. Stressful life events and disordered eating behaviors: findings from project EAT. J Adolesc Health 2008;43:514-6.

100. Keel PK, Klump KL, Miller KB, et al.
Shared transmission of eating disorders and anxiety disorders. Int $\mathbf{J}$ Eat Disord 2005;38:99-105.

101. Lilenfeld LRR, Ringham R, Kalarchian MA, Marcus MD. A family history study of binge-eating disorder. Compr Psychiatry 2008;49:247-54.

102. Sternheim L, Startup H, Saeidi S, et al. Understanding catastrophic worry in eating disorders: process and content characteristics. J Behav Ther Exp Psychiatry 2012;43:1095-103.

103. Konstantellou A, Campbell M, Eisler I, et al. Testing a cognitive model of generalized anxiety disorder in the eating disorders. J Anxiety Disord 2011;25:864-9.
104. Sassaroli S, Bertelli S, Decoppi M, et al. Worry and eating disorders: a psychopathological association. Eat Behav 2005;6:301-7.

105. Basson RA, Mwaba K, Rossouw RJ, et al. The significance of sub-threshold symptoms of anxiety in the aetiology of bruxism. S Afr J Psychol 2010;40:174-81.

106. Tanaka OM, Vitral RWF, Tanaka GY, et al. Nailbiting, or onychopagia: a special habit. Am J Orthod Dentofacial Orthop 2008;134:305-8.

107. Craske MG, Rauch SL, Ursano R, et al. What is an anxiety disorder? Depress Anxiety 2009;26:1066-85. 